\title{
Strategi Pengelolaan tempat pemrosesan akhir (TPA ) Sampah Batu Canai di Kelurahan Pematang Reba Indragiri Hulu
}

\author{
Amalia Prafitra Harman ${ }^{1}$, Yusni Ikhwan Siregar ${ }^{2}$, Ridwan Manda Putra ${ }^{2}$ \\ ${ }^{1}$ Environment Officer di First Resources Group \\ ${ }_{2}^{2}$ Pascasarjana Ilmu Lingkungan Program Pascasarjana Universitas Riau \\ *Correspondent email : amaliapharman@gmail.com
}

\begin{abstract}
.
To solve the waste problem in Indragiri Hulu Regency, the Regency Government built a Landfill (TPA). This waste Landfill (TPA) is located at Jalan Batu Canai, Pematang Reba Village, Rengat Barat District. However, the management of this TPA has experienced various obstacles so that it does not run optimally so it is interesting for further research. This research was conducted in August 2020 at the Batu Canai waste landfill (TPA) using survey methods, literature study and interviews. The type of data used in the form of a combination of quantitative and qualitative research will be described descriptively. The variables of this study include 1.) The existing condition of Batu Canai Waste Landfill (TPA) Pematang Reba Village, 2) The impact of the existence of Batu Canai Final Disposal Site (TPA) of Batu Canai Garbage in Pematang Reba Village on the environment, social and economy according to the perceptions of the community around the TPA ,3) Management strategy of Batu Canai waste landfill (TPA) Pematang Reba Village. The existing condition of TPA Batu Canai in terms of facilities and infrastructure is quite adequate, although some infrastructure and operational facilities are damaged. From the calculation results, the estimated service life of Batu Canai waste landfill (TPA) is 8 years and 9 months. For the impact of the existence of TPA Batu Canai, according to the community's perception around the TPA, from a socio-economic perspective, their response was positive and from an environmental perspective, their response was negative. Meanwhile, the alternative management strategies for Batu Canai waste landfill were analyzed through SWOT analysis. From the results of the SWOT analysis, it was found that the condition of the TPA was in Quadrant III and the right alternative strategy for managing the Batu Canai Final Processing Site (TPA) in Pematang Reba Village was a WO (Weaknesses-Opportunities) strategy, namely 1) Optimizing the Controlled landfill system, 2) Support Government to establish a special agency for managing TPA, 3) Utilizing good waste processing technology to process organic waste into bio energy, 4) Empowering and fostering communities to establish a Waste Bank.
\end{abstract}

Keywords: Strategy; TPA Waste Management; TPA Batu Canai

Peningkatan jumlah tumpukan sampah sampah jika tidak dikelola dengan baik dapat menimbulkan berbagai implikasi. Pada Tahun 1995 Pemerintah daerah Kabupaten Indragiri Hulu membangun sebuah Tempat Pemrosesan Akhir(TPA) Sampah Batu Canai untuk melayani 5 wilayah pelayanan sampah yakni Kecamatan Rengat, Rengat Barat, Pasir Penyu, Seberida dan Peranap.m Keberadaan Tempat Pemrosesan Akhir (TPA) Batu Canai yang berlokasi di Kelurahan Pematang Reba ini diharapkan dapat mengatasi permasalahan sampah yang ada di Kabupaten Indragiri Hulu. Namun di satu sisi operasional TPA Batu Canai ini juga memberikan dampak terhadap kondisi lingkungan dan sosial terutama bagi pemukiman masyarakat yang berada di sekitar daerah tersebut. Namun melalui TPA ini jika sampah dapat dikelola dengan baik akan menimbulkan dampak positif dari segi ekonomi seperti peningkatan kesejahteraan masyarakat. Operasional dan pengelolaan TPA Batu Canai.

Pengelolaan TPA Batu Canai berada di bawah wewenang Seksi Pengelolaan TPA pada Dinas Pekerjaan Umum dan Penataan Ruang (PUPR) Kabupaten Indragiri Hulu. Dalam operasional TPA Batu Canai ini mengalami berbagai permasalahan dan kendala baik dari segi internal maupun eksternal TPA sehingga perlu dilakukan analisis strategi yang efektif dan efisien agar pengelolaan TPA Batu Canai optimal.

\section{METODE PENELITIAN}

Penelitian dilakukan pada bulan Agustus 2020 di Tempat Pemrosesan Akhir (TPA) Sampah Batu Canai dengan metode survei, study literature dan wawancara. Penentuan responden dari masyarakat sekitar dilakukan secara purposive sampling dengan kriteria yang dapat mewakili, yakni masyarakat yang tinggal disekitar wilayah TPA dan masyarakat yang bekerja sebagai pemulung. Disamping itu, juga dilakukan wawancara mendalam dengan Pengelola TPA Batu Canai Kepala Seksi Pengelolaan TPA di Dinas 
Pekerjaan Umum dan Penataan Ruang (PUPR) Kabupaten Indragiri Hulu dan Kepala Seksi Pengangutan Persampahan di Dinas Lingkungan Hidup sebagai responden kunci.

Untuk menganalisis kondisi eksisting Tempat Pembuangan Akhir (TPA) Sampah Batu Canai di Kelurahan Pematang Reba dilakukan dengan cara observasi lapangan dan dengan menghitung proyeksi masa layanan landfill. Kondisi eksisting TPA yang di teliti yaitu 1) Bentuk dan struktur organisasi Pengelola TPA Batu Canai, 2) Infrastruktur yang ada untuk mendukung pengelolaan TPA Batu Canai

Untuk menganalisis dampak keberadaan Tempat Pembuangan Akhir (TPA) Sampah Batu Canai terhadap lingkungan, sosial dan ekonomi menurut persepsi masyarakat dilakukan melalui kuisioner dan wawancara dengan responden. Responden penelitian ini adalah masyarakat yang tinggal disekitar TPA Batu Canai dan masyarakat yang bekerja sebagai pemulung yang berjumlah 20 orang.

Analisis SWOT didasarkan logika yang dapat memaksimalkan strength (kekuatan) dan opportunity (peluang), namun secara bersamaan dapat meminimalkan weakness (kelemahan) dan threat (ancaman) menggunakan matriks SWOT. Matriks SWOT ada dua yaitu Matriks Internal Factor Analysis Summary (IFAS) dan Matriks Eksternal Factor Analysis Summary (EFAS), Kemudian masing-masing IFAS dan EFAS diberi bobot dan Rating untuk menghitung Skor. Kemudian dibuat dagram cartesius SWOT. Untuk sumbu $\mathrm{X}$ adalah selisih antara total Strength dan total Weakness, sedangkan untuk nilai sumbu Y didapat dari selisih antara total antara Opportunities dan total Threat. Kemudian dibuat titik perpotongan antara sumbu $\mathrm{x}$ dan $\mathrm{y}$.

\section{HASIL DAN PEMBAHASAN}

\section{Kondisi Eksisting Tempat Pemrosesan Akhir (TPA) Sampah Batu Canai Di Kelurahan Pematang Reba Indragiri Hulu}

\section{Bentuk dan Struktur Organisasi Pengelola TPA}

Berdasarkan hasil observasi secara langsung susunan Organisasi Perangkat Daerah/Instansi yang berwenang dalam pengelolaan TPA di Kabupaten Indragiri Hulu dan persampahan berada di bawah Dinas Pekerjaan Umum dan Penataan Ruang kabupaten dan Dinas Lingkungan Hidup Indragiri Hulu yang merupakan satu Organisasi Perangkat Daerah yang mengurus masalah persampahan dari sumber sampah hingga ke TPA. Struktur organisasi nya yakni memiliki seorang Kepala bidang, Kepala Seksi dan beberapa orang staf.

TPA saat ini berada di bawah pengawasan Bidang Kebersihan dan Pertamanan Seksi Pengelolaan TPA. Seksi ini dibawahi 1 orang Kepala Seksi yang memiliki 9 orang staf. Dan untuk tupoksi pengelolaan dan pengangkutan sampah berada pada Dinas Lingkungan Hidup Kabupaten Indragiri Hulu dibawah Seksi Pengelolaan Persampahan dan Pengangkutan dibantu oleh 1 orang staf dan 1 orang tenaga Honorer. Seksi Pengelolaan Persampahan dan Pengangkutan ini menangani masalah penyediaan sarana dan prasarana persampahan, pemungutan retribusi sampah, serta penyuluhan dan pengaduan apabila ada permasalahan sampah.

\section{Infrastruktur Tempat Pemrosesan Akhir (TPA) Sampah Batu Canai Di Kelurahan Pematang Reba Indragiri Hulu}

\section{Umum dan penunjang}

Kantor pengelola. Kondisi bangunannya yang masih baik dan masih layak untuk digunakan sebagai kantor operasional TPA. Tetapi belum dipergunakan sebagaimana mestinya.

Pintu gerbang masuk. jalan masuk dan papan nama. Pintu masuk sudah ada pagar yang terbuat dari semen dan plang nama TPA sebagai penanda lokasi. Untuk jalan utama masuk kedalam TPA kondisi jalan masuk sudah aspal dengan lebar jalan $\pm 8 \mathrm{~m}$, sehingga memungkinan masuknya 2 kendaraan bersamaan.

Saluran drainase. Sepanjang jalan masuk ke dalam TPA dan tempat penimbunan sampah adanya drainase yang terbuat dari semenisasi

Pagar. TPA yang ada di kelilingi oleh pagar yang terbuat dari batu bata dan semen. Kondisi fisiknya saat ini masih baik. 
Timbangan. Untuk saat ini kondisi dari timbangan kendaraan operasional sampah nya sudah rusak dan tidak berfungsi sebagaimana mestinya.

Instalasi pengolah sampah. 1) Fasilitas kompos tahap pertama, merupakan tempat pemilahan. 2) Fasilitas kompos tahap kedua yang merupakan pembuatan komposnya. Namun pembuatan kompos belum pernah dijalankan dikarenakan pihak pengelola TPA kekurangan biaya operasional dari Dinas Pekerjaan Umum dan Penataan Ruang Kabupaten Indragiri Hulu.

Garasi kendaraan operasional TPA. Terdapat garasi kendaraan untuk tempat parkir mobil operasional TPA yang kondisi fisiknya masih baik. Tetapi untuk saat ini kebanyakan mobil operasional ditempatkan dibekas kantor UPT Kebersihan di Kecamatan Rengat.

Workshop.Tempat Pemrosesan Akhir (TPA) Sampah Batu Canai Kecamatan Rengat Barat tersedia juga tempat workshop yang merupakan sarana tempat perbaikan kendaraan operasional kendaraan TPA

\section{Perlindungan lingkungan}

Drainase landfill. Tidak tersedianya drainase pada landfill serta pipa penampung air lindi, sehingga terlihat adanya air yang tergenang didekat tumpukan sampah.

Instalasi pengolahan lindi (IPL). Tersedianya pengolahan lindi yang terdiri dari 3 kolam. Tetapi dari observasi lapangan yang telah dilakukan kondisi eksisiting yang ada pada kolam tersebut hanya terisi oleh air hujan.

Buffer zone. Lokasi TPA ini masih dikeliling oleh tumbuhan hijau terhampar luas.

\section{Fasilitas operasional}

\section{Jalan operasi.}

Tersedianya jalan operasi pada TPA yang berupa jalan aspal untuk bisa dilewati oleh kendaraan operasional. Sedangkan jalan menuju IPL masih jalan tanah ketika hari hujan akan menyebabkan jalanan licin dan menimbulkan terdapatnya jalanan yang sudah berlubang tergenang oleh air.

\section{Sarana Pengangkutan sampah}

Sarana pengangkutan sampah di TPA Batu canai dapat dilihat pada Tabel 1.

Tabel 1. Sarana pengangkutan sampah menuju TPA Batu Canai

\begin{tabular}{llccccc}
\hline No & \multicolumn{1}{c}{ Alat Angkut } & \multirow{2}{*}{$\begin{array}{c}\text { Kapasitas } \\
(\mathrm{m} 3)\end{array}$} & $\begin{array}{c}\text { Jumlah } \\
(\text { Unit })\end{array}$ & $\begin{array}{c}\text { Baik dan } \\
\text { Beroperasi }\end{array}$ & Rusak & \multirow{2}{*}{$\begin{array}{c}\text { Ritasi } \\
\text { (kali) }\end{array}$} \\
\hline 1 & Gerobak Sampah & 50 & 12 & 6 & 6 & 2 \\
2 & Gerobak Motor sampah & 150 & 4 & 3 & 1 & 3 \\
3 & Motor Sampah (Roda & 200 & 1 & 1 & 0 & 4 \\
& Tiga) & 1300 & 5 & 5 & 0 & 4 \\
4 & Armroll Truck & 1300 & 1 & 1 & 0 & 2 \\
\hline
\end{tabular}

Sarana pemindahan sampah yang digunakan berupa TPS. TPS yang tersedia sebanyak 2 unit di Kecamatan Seberida dan Peranap. Sarana pengumpulan sampah yang dilakukan oleh masyarakat/rumah tangga ke TPS terdekat.

\section{Pengoperasian TPA}

Berdasarkan hasil wawancara dengan pengelola Tempat Pemrosesan Akhir (TPA) Sampah Batu Canai bahwa jam kerja operasi sampah yang masuk ke TPA dimulai pada pagi hari yaitu mulai pukul 07:00 sampai 18:00. Ada 1 orang petugas yang bekerja sebagai pengawas di TPA, bekerja dalam shift pagi yaitu dari Pukul 07:00-12:00 dan berikutnya dilanjutkan pada pukul 12:00-18:00 untuk shift sore. 
Volume Sampah yang masuk ke Tempat Pemrosesan Akhir (TPA) Sampah Batu Canai Pematang Reba

Tabel 2. Volume timbulan Sampah yang masuk Ke Tempat Pemrosesan Akhir (TPA) Sampah Batu Canai

\begin{tabular}{|c|c|c|c|c|c|c|}
\hline No & Tahun & $\begin{array}{l}\text { Jumlah } \\
\text { (Jiwa) }\end{array}$ & Penduduk & $\begin{array}{l}\text { Volume } \\
\left(\mathrm{m}^{3} / \text { tahun }\right)\end{array}$ & Sampah & Volume Sampah (m ${ }^{3} /$ hari) \\
\hline 1 & 2014 & 210.465 & & 19,208 & & 52.6 \\
\hline 2 & 2015 & 214.944 & & 21,705 & & 59.5 \\
\hline 3 & 2016 & 219.302 & & 25,189 & & 69.0 \\
\hline 4 & 2017 & 220.588 & & 27,713 & & 75.9 \\
\hline 5 & 2018 & 227.807 & & 30,717 & & 84.2 \\
\hline 6 & 2019 & 228.952 & & 34,923 & & 95.7 \\
\hline
\end{tabular}

Sumber: Dinas Lingkungan Hidup Kab.Indragiri Hulu dan Data Olahan, 2020

\section{Kegiatan Pengurangan Sampah}

Berdasarkan hasil survey jumlah timbulan sampah yang dikelola oleh pemulung Tempat Pemrosesan Akhir (TPA) Sampah Batu Canai responden yang diambil berjumlah 10 orang pemulung. Perhitungan timbulan sampah dilakukan dengan menimbang berat sampah yang dikumpulkan oleh setiap pemulung dengan karung berukuran $50 \mathrm{~kg}$ setiap harinya selama 8 hari penelitian. Berat sampah harian yang dikelola oleh pemulung Tempat Pemrosesan Akhir (TPA) Sampah Batu Canai dapat dilihat pada Gambar 1.

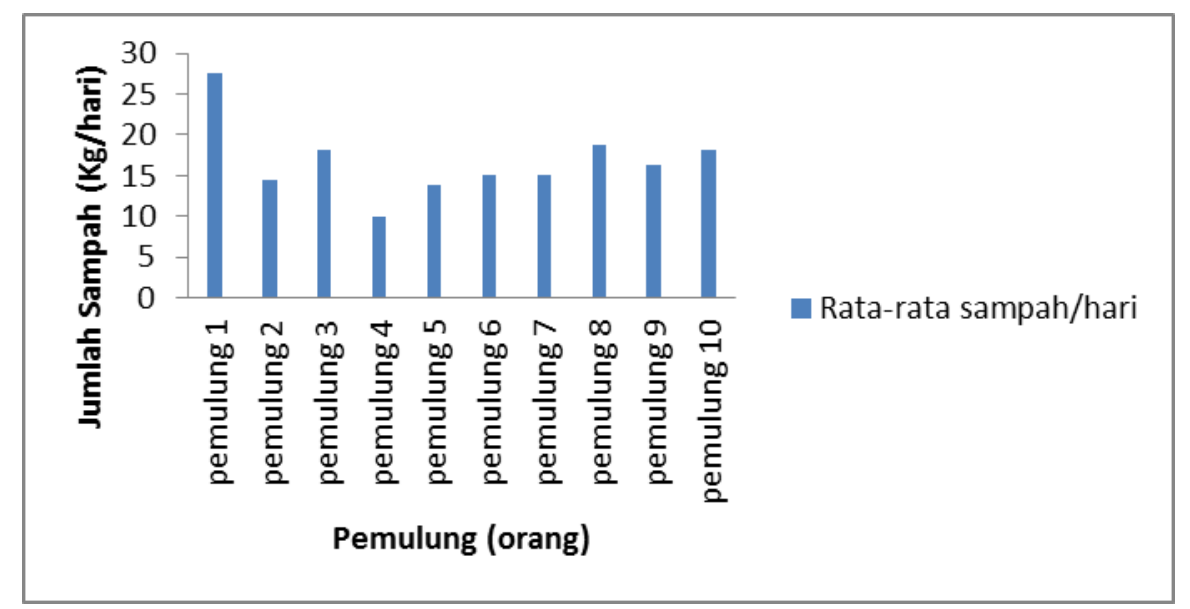

Gambar 1. Rata-rata Sampah yang Dikelola oleh Pemulung di Tempat Pemrosesan Akhir (TPA) Sampah Batu Canai Per hari

Berdasarkan pada grafik diatas, menunjukkan bahwa pemulung mampu mengumpulkan sampah sebesar 16,69 Kg per harinya. sedangkan jumlah timbulan sampah yang yang mampu dikumpulkan dan dikelola oleh seluruh pemulung di Tempat Pemrosesan Akhir (TPA) Sampah Batu Canai setiap harinya adalah sebesar $134 \mathrm{~kg}$ per hari dan hanya $10 \%$ dari jumlah pemulung yang mengumpulkan sampah kurang dari $100 \mathrm{~kg}$ selama 8 hari.

Jika berpedoman pada Peraturan Bupati Tahun 2019 kegiatan pengurangan yang telah ada belum mampu mencapai target yang diharapkan Pemerintah Daerah. Oleh karena itu untuk mencapai target pengurangan sampah tahun 2025.

\section{Perkiraan Masa Layanan Landfill Tempat Pemrosesan Akhir (TPA) Sampah Batu Canai Pematang Reba}

Prediksi jumlah sampah Kecamatan Rengat Barat pada tahun yang akan datang, terlebih dahulu mencari nilai rata-rata jumlah volume sampah tiap tahunnya. Mencari rata-rata jumlah volume sampah per tahun dan perkiraan masa layanan landfill seperti perhitungan pada Tabel 3. 
Tabel 3. Perhitungan proyeksi masa layanan landfill TPA Batu Canai

\begin{tabular}{lll}
\hline No. & Langkah Perhitungan & Hasil \\
\hline 1 & Mencari persentase sampah per tahun & $13 \%$ \\
2 & $\begin{array}{l}\text { Menghitung volume pertambahan sampah } \\
\text { per tahun }\end{array}$ & $15,715 \mathrm{~m}^{3}$ \\
3 & $\begin{array}{l}\text { Mencari r (laju penambahan sampah) per } \\
\text { tahun }\end{array}$ & $2,54 \%=0,025$ \\
4 & $\begin{array}{l}\text { Prediksi pertambahan sampah di Tahun } \\
\text { 2020 }\end{array}$ & $50.811,5 \mathrm{~m}^{3}$ \\
5 & Penentuan kapasitas landfill & $500.000 \mathrm{~m}^{3}$ \\
6 & $\begin{array}{l}\text { Perhitungan sampah perbulan pada Tahun } \\
\text { 2028 }\end{array}$ & $96,92 \mathrm{~m}^{3} / \mathrm{hari}$ \\
7 & $\begin{array}{l}\text { Perhitungan sisa lahan setelah Tahun 2028 } \\
8\end{array}$ & $27,826 \mathrm{~m}^{3}$ \\
\hline
\end{tabular}

Tabel 4. Perhitungan volume sampah di Tempat Pemrosesan Akhir (TPA) Sampah Batu Canai Kecamatan Rengat Barat

\begin{tabular}{|c|c|c|c|c|c|c|c|}
\hline No & Tahun & $\begin{array}{c}\text { Volume Sampah } \\
\left(\mathrm{m}^{3} / \text { tahun }\right)\end{array}$ & $\begin{array}{c}\text { Reduksi } \\
\text { pemulung } \\
(5 \%)\end{array}$ & $\begin{array}{c}\text { Volume } \\
\text { tereduksi } \\
\left(\mathrm{m}^{3}\right)\end{array}$ & $\begin{array}{c}\text { Sisa volume } \\
\text { sampah }\left(\mathrm{m}^{3}\right)\end{array}$ & $\begin{array}{c}\text { Vol } \\
\text { sampah } \\
\text { ditimbun } \\
\left(\mathrm{m}^{3}\right)\end{array}$ & $\begin{array}{c}\text { Kumulatif } \\
\left(\mathrm{m}^{3}\right)\end{array}$ \\
\hline 1 & 2014 & 19.208 & 0,05 & 960,40 & $18.247,60$ & $5.474,28$ & $5.474,28$ \\
\hline 2 & 2015 & 21.705 & 0,05 & 1085,25 & $20.619,75$ & $6.185,93$ & $11.660,21$ \\
\hline 3 & 2016 & 25.189 & 0,05 & 1259,45 & $23.929,55$ & $7.178,87$ & $18.839,07$ \\
\hline 4 & 2017 & 27.713 & 0,05 & 1385,65 & $26.327,35$ & $7.898,21$ & $26.737,28$ \\
\hline 5 & 2018 & 30.717 & 0,05 & 1535,85 & $29.181,15$ & $8.754,35$ & $35.491,62$ \\
\hline 6 & 2019 & 34.923 & 0,05 & 1746,15 & $33.176,85$ & $9.953,06$ & $45.444,68$ \\
\hline 7 & 2020 & 35.772 & 0,05 & 1788,58 & $33.983,05$ & $10.194,91$ & $55.639,59$ \\
\hline 8 & 2021 & 36.641 & 0,05 & 1832,04 & $34.808,84$ & $10.442,65$ & $66.082,24$ \\
\hline 9 & 2022 & 37.531 & 0,05 & 1876,56 & $35.654,69$ & $10.696,41$ & $76.778,65$ \\
\hline 10 & 2023 & 38.443 & 0,05 & 1922,16 & $36.521,10$ & $10.956,33$ & $87.734,98$ \\
\hline 11 & 2024 & 39.377 & 0,05 & 1968,87 & $37.408,56$ & $11.222,57$ & $98.957,55$ \\
\hline 12 & 2025 & 40.334 & 0,05 & 2016,72 & $38.317,59$ & $11.495,28$ & $110.452,82$ \\
\hline 13 & 2026 & 41.314 & 0,05 & 2065,72 & $39.248,71$ & $11.774,61$ & $122.227,43$ \\
\hline 14 & 2027 & 42.318 & 0,05 & 2115,92 & $40.202,45$ & $12.060,74$ & $134.288,17$ \\
\hline 15 & 2028 & 43.347 & 0,05 & 2167,34 & $41.179,37$ & $12.353,81$ & $146.641,98$ \\
\hline 16 & 2029 & 44.400 & 0,05 & 2220,00 & $42.180,03$ & $12.654,01$ & $159.295,99$ \\
\hline
\end{tabular}

Sumber: Data Olahan, 2020

Berdasarkan perhitungan prediksi dapat diketahui masa layanan sampah dapat di terima pada Tahun 2028 pada bulan ke 9 sehingga total dari tahun 2020 untuk Tempat Pemrosesan Akhir (TPA) Sampah Batu Canai Di Kelurahan Pematang Reba dapat melayani hingga 8 tahun 2 bulan. Persentase reduksi pemulung diasumsikan $5 \%$ dari total sampah yang masuk pertahunnya. Untuk lebih jelas volume sampah pertahunnya dapat dilihat pada Tabel 4.. Proyeksi volume sampah di Kabupaten Indragiri Hulu hingga Tahun 2029.

Berdasarkan proyeksi tersebut maka Kabupaten Indragiri Hulu harus memiliki perencanaan lebih lanjut mengenai kondisi TPA. Ada beberapa pilihan alternatif yang bisa dilakukan sesuai dengan PerMen PU No. 03/PRT/M/2013, yaitu 1) Alokasi lahan TPA yang baru dengan merubah strategi pengelolaannya. 2) Rehabilitasi dan melakukan kegiatan maintenance pada TPA yang ada dengan tetap mencari penyiapan lokasi TPA baru. 3) Jika sudah ditentukan lokasi TPA baru yang akan dipergunakan 
maka direncanakan untuk penutupan TPA lama dan dilakukan pemantauan TPA yang telah ditutup selama 20 tahun secara berkala.

\section{Dampak Keberadaan TPA menurut persepsi masyarakat}

\section{Dampak Positif Keberadaan Tempat Pemrosesan Akhir (TPA) Sampah Batu Canai Pematang Reba}

Keberadaan TPA yang ada di Pematang Reba Kecamatan Rengat Barat juga memiliki dampak positif yang dirasakan oleh masyarakat di sekitar TPA yaitu dengan adanya terbuka lapangan pekerjaan. Hasil obesrvasi dan wawancara secara langsung kepada masyarakat yang ada disekitar TPA baik yang bekerja sebagai pemulung menyatakan bahwa dengan adanya keberadaan TPA menyebabkan terbukanya lapangan kerja bagi penduduk setempat. Masyarakat yang bekerja sebagai pemulung di sekitar TPA berpeluang memiliki sumber penghasilan baru, asalkan mau berkotor-kotor itu pernyataan salah satu responden yang ada dilapangan. Adanya TPA telah ikut berperan dalam meningkatkan kesejahteraan warga masyarakat sekitarnya. Setidaknya mereka memiliki pemasukan setiap harinya walaupun tidak menentu jumlah yang didapatnya. Tetapi dengan hasil tersebut sebagian masyarakat memiliki keluarga yang bisa bersekolah hingga jenjang perkuliahan.

Handono (2010) dalam penelitiannya mengkaji tentang manfaat utama TPA berupa terbukanya kesempatan kerja dan berusaha bagi warga sekitar, dalam bentuk sebagai karyawan tetap di TPA, supir dan kernet, pemulung sampah dan usaha pengumpul barang bekas serta usaha warung makanan kecil. Berdasarkan hasil wawancara dengan responden jumlah pemulung perhari diperkirakan mencapai 10-15 orang, dengan penghasilan sekitar $\mathrm{Rp} 50.000$-/hari atau lebih dan bisa perbulannya para pemulung mendapatkan rata-rata sekitar Rp 300.000-750.000/bulan nilai ini bisa berubah tergantung dari banyak sedikitnya hasil sampah yang bisa dikumpulkan. Sampah hasil peengumpulan dijual kepada pedagang pengumpul (lapak) yang ada di sekitar TPA.

Untuk saat ini lapangan pekerjaan yang ada hanya dalam bentuk pengumpulan sampah an-organik. Belum ada pengumpulan sampah berupa organik yang diolah menjadi kompos, dikarenakan belum adanya fasilitas yang diberikan Pemerintah Daerah dalam pengelolaan sampah di Tempat Pemrosesan Akhir (TPA) Sampah Batu Canai. Sedangkan pembuatan kompos skala besa bisa menjadi peluang yang besar didukung dengan jumlah sampah organik yang dihasilkan oleh kabupaten Indragiri Hulu cukup besar.

\section{Dampak Negatif Keberadaan Tempat Pemrosesan Akhir (TPA) Sampah Batu Canai Pematang Reba}

\section{Bau}

Hasil wawancara kepada warga yang tinggal di sekitar TPA memberikan pernyataan terhadap bau yang ditimbulkan dari sampah. Keluhan tersebut yang dirasakan hampir merata terhadap bau yang ditimbulkan dari TPA. Pada saat kondisi normal, masalah bau busuk sebenarnya tidak ditemui. Bau tersebut muncul menurut mereka tidak terjadi secara rutin, namun terkadang ada dikarenakan adanya arah angin dengan durasi yang juga tidak menentu namun biasanya antara 5 hingga 15 menit. Bau ini juga muncul ketika hari hujan terjadi. Pada dasarnya masyarakat sudah maklum dengan kondisi bau sampah, mengingat tempat tinggal mereka berdekatan dengan TPA, namun tetap saja penduduk merasa terganggu.

Selain akibat bau dari keberadaan TPA, yang dikeluhkan masyarakat Di sekitar TPA adalah truk sampah yang sudah kosong dan masih kotor terkadang menebarkan bau yang bisa lebih keras ketimbang truk yang masih terisi muatan. Sehingga dapat menggangu masyarakat yang bertempat tinggal di sekitar TPA. Dapat disimpulkan bahwa bau yang ditimbulkan ini akibat adanya proses pembusukan pada sampah organik oleh bakteri yang ada disampah tersebut. Bau ini salah satunya adalah gas metan yang sangat berbahaya jika terlalu lama terpapar. Kondisi ini bukan saja dari sampah yang masuk ke TPA tetapi sampah yang sudah tertumpuk lama di dalam TPA.

\section{Lalat}

Hasil wawancara yang dilakukan dilapangan mengenai lalat juga menjadi keluhan bagi masyarakat di sekitar TPA. Lalat tersebut datang pada saat sesudah hujan turun dan akibat dari ceceran sampah di sepanjang jalan menuju TPA. Jika musim hujan datang keberadaan lalat akan mengganggu masyarakat di sekitar TPA. Hal ini juga salah satu keresahan yang dirasakan oleh masyarakat, tetapi karena sudah lama mereka tinggal di lingkungan TPA menjadi hal biasa yang dialami. 
Keresahan masyarakat akan dapat diatasi jika pengelolaan sampah dilakukan secara baik. Permasalahan lalat tidak akan muncul jika penyemprotan anti lalat dilakukan secara rutin terutama di saat musim hujan. Penyemprotan akan menghilangkan bau sampah yang mengundang lalat. Untuk mengatasi masalah ini pihak Dinas Kesehatan Kabupaten Indragiri Hulu dengan melakukan kegiatan penyemprotan setiap 3 bulan sekali. Tetapi untuk saat ini sudah mulai berkurang periode penyemprotan tersebut dikarenakan terkendala biaya.

Lalat merupakan vektor hewan pembawa penyakit. Dengan hinggapnya lalat pada sampah dan hinggap di makanan maka akan meninggalkan bakteri pada tempat tersebut. Sehingga bisa menyebabkan penyakit yang dapat diderita bisa berupa diare, disentri, kolera dan penyakit cacingan. Hal yang seperti belum terlalu menjadi perhatian bagi pemerintah (Sabella, 2014).

\section{Pencemaran air oleh lindi}

Dampak keberadaan Tempat Pemrosesan Akhir (TPA) Sampah dapat menyebabkan sumur masyarakat dan tanah tercemar. Pencemaran air ini bisa disebabkan dari leacheate sampah yang masuk ke dalam tanah membawa kandungan bahan berbahaya dari sampah ikut masuk ke dalam air (Kasam, 2011). Berdasarkan survei untuk kondisi air tanah rumah penduduk di dekat TPA belum adanya terindikasi tercemar oleh TPA. Dilihat secara visual airnya masih bersih, tidak berbau dan tidak keruh. Tetapi untuk dijadikan sebagai konsumsi minum masyarakat masih khawatir dan lebih aman menggunakan air isi ulang, karena walaupun kondisi visualnya baik tetapi rasa kekhawatiran masyarakat akan tercemar cukup tinggi.

Sedangkan untuk air lindi hasil sampingan dari sampah tidak tertampung dengan baik sehingga kolam pengolahan yang ada hanya sebagai penampung air hujan serta tidak benar-benar digunakan sebagai pengolahan air lindi. Sehinggan air lindi yang ditimbulkan oleh pembusukan sampah tergenang dibeberapa tempat dan menimbulkan banyaknya genangan disekitar tumpukan sampah di TPA. Karena tidak adanya sistem pengumpul lindi berupa drainase dan pipa yang menyalurkan ke kolam pengolahan lindi.

\section{Penyakit yang diderita pemulung dan penggunaan Alat Pelindung Diri (APD) keselamatan kerja}

Responden pemulung yang ditemui pada saat wawancara, mengenai kesehatan fisik maupun mental selama mereka bekerja di TPA belum ada yang mengalami gangguan dan selama mereka bekerja hanya mengalami sakit berupa demam, batuk dan influenza. Belum ada penyakit secara spesifik yang ditimbulkan karena bekerja ataupun tinggal di sekitar TPA.

Banyak penyakit yang muncul bagi pemulung yang bekerja di TPA dari tidak menggunakan APD (Alat Pelindung Diri). Alat Pelindung Diri rata-rata pemulung gunakan pada saat bekerja sangat sederhana seperti sepatu, topi, masker, sepatu booth dan lain-lain, yang tidak memenuhi persyaratan sebagai pelindung yang dapat memberikan keamanan dan kenyamanan terhadap ancaman gangguan kesehatan.

Penyakit yang bisa dialami oleh masyarakat yang tinggal dan bekerja di sekitar TPA adalah penyakit Diare. Penyakit diare didefinisikan sebagai buang air besar (defekasi) dengan jumlah tinja yang lebih banyak dari biasanya (normal 100-200 $\mathrm{ml}$ per jam tinja), dengan tinja berbentuk cairan atau setengah padat, dapat pula disertai frekuensi defekasi yang meningkat. Selanjutnya adalah penyakit ISPA (infeksi saluran pernapasan atas), yang dialami oleh masyarakat di sekitar TPA. Penyakit ISPA (infeksi saluran pernapasan akut) adalah infeksi pada saluran pernapasan baik saluran pernapasan atas atau bawah.Masalah lainnya adalah munculnya penyakit kulit. Penyakit kulit adalah setiap yang disebabkan oleh pekerjaan atau lingkungan kerja berupa faktor risiko mekanik, fisik, kimia, biologis dan psikologis Penyakit lainnya yang sering dialami oleh masyarakat di sekitar TPA adalah penyakit cacingan. Infeksi kecacingan yang disebabkan oleh Soil Transmitted Helminths (STH) merupakan masalah kesehatan masyarakat. Infeksi kecacingan tergolong penyakit neglected disease yaitu infeksi yang kurang diperhatikan dan penyakitnya bersifat kronis tanpa menimbulkan gejala klinis yang jelas dan dampak yang ditimbulkannya baru terlihat dalam jangka panjang. Terakhir adalah penyakit Malaria. Penyakit malaria pada manusia disebabkan plasmodium Malriae, penularan malaria dilakukan oleh nyamuk betina dari tribus Anoples. Terjadinya peningkatan penyakit malaria disebabkan oleh masih kurangnya pengendalian vektor, kebiasaan tidak menggunakan kelambu, kebiasaan tidak mengunakan anti nyamuk, kebiasaan 
menggantung pakaian dan jarangnya ada penyemprotan (fogging) dari Dinas Kesehatan Kabupaten Indragiri Hulu untuk mengendalikan penyebaran nyamuk.

\section{Strategi Pengelolaan Tempat Pemrosesan Akhir (TPA) Sampah Batu Canai Di Kelurahan Pematang} Reba

\section{Identifikasi dan Inventarisasi Unsur Strategi Faktor Internal dan Eksternal}

Adapun hasil analisis isu strategis rangkumannya dapat dilihat pada Tabel 5.

Tabel 5. Analisis faktor internal dan eksternal

\begin{tabular}{|c|c|c|}
\hline No. & Isu Utama & Unsur SWOT \\
\hline 1 & Sarana dan prasarana pengolahan sampah & Strengths \\
\hline 2 & Controlled landfill & Kekuatan \\
\hline 3 & Akses dan sarana transportasi menuju TPA & \\
\hline 4 & Lahan yang luas untuk proses pengolahan sampah & \\
\hline 1 & Anggaran Pengelolaan Sampah terbatas & Weaknesses \\
\hline 2 & Jumlah dan keahlian SDM masih terbatas & Kelemahan \\
\hline 3 & $\begin{array}{l}\text { Pembagian tugas operasioanl dan maintenance belum dibagi } \\
\text { dengan jelas }\end{array}$ & (W) \\
\hline 4 & Biaya Operasional pengelolaan TPA (Controlled landfill) & \\
\hline 5 & Status Kepemilikan lahan & \\
\hline 6 & Pemanfaatan teknologi pengolahan sampah tidak optimal & \\
\hline 1 & Sumber Sampah & Opportunities \\
\hline 2 & Dukungan dari pemerintah daerah sangat baik & Peluang \\
\hline 3 & $\begin{array}{l}\text { Potensi bisnis daur ulang sampah yang saat ini menjanjikan } \\
\text { keuntungan }\end{array}$ & (O) \\
\hline 4 & sampah organic yang bisa dijadikan sebagai bio energy & \\
\hline 5 & Pihak swasta yang mendirikan Bank Sampah & \\
\hline 1 & $\begin{array}{l}\text { Kesadaran masyarakat untuk memilah dan mengelola sampah } \\
\text { masih minim }\end{array}$ & $\begin{array}{l}\text { Threats } \\
\text { Ancaman }\end{array}$ \\
\hline 2 & Perubahan Teknologi pengolahan sampah yang semakin canggih & $(\mathrm{T})$ \\
\hline 3 & Tidak adanya kepastian hukum tentang operasional TPA & \\
\hline 4 & $\begin{array}{l}\text { Kurangnya kerja sama antar instansi pemerintah dalam } \\
\text { operasional TPA }\end{array}$ & \\
\hline
\end{tabular}

Analisis SWOT Pada Tempat Pemrosesan Akhir (TPA) Sampah Batu Canai Di Kelurahan Pematang Reba

\section{Analisis Internal (IFAS)}

Hasil perhitungan terhadap factor-faktor internal TPA Sampah Batu Canai Pematang Reba dapat dilihat pada Tabel 6 dan Tabel 7.

Tabel 6. Hasil Perhitungan faktor-faktor Kekuatan pada Tempat Pemrosesan Akhir (TPA) Sampah Batu Canai Pematang Reba

\begin{tabular}{lllll}
\hline \multicolumn{2}{l}{ Strenghts (S) } & & & \\
\hline No. & Kekuatan & Bobot & Rating & Skor \\
1 & Sarana dan prasarana pengolahan sampah & 0.20 & 4 & 0.80 \\
2 & Controlled landfill & 0.40 & 2 & 0.80 \\
3 & Akses dan sarana transportasi menuju TPA & 0.20 & 3 & 0.60 \\
4 & Lahan yang luas untuk proses pengolahan sampah & 0.20 & 1 & 0.20 \\
\hline Total & & 1 & 10 & 2.40 \\
\hline
\end{tabular}


Tabel 7. Hasil Perhitungan faktor-faktor Kelemahan pada Tempat Pemrosesan Akhir (TPA) Sampah Batu Canai Pematang Reba

\begin{tabular}{|c|c|c|c|c|}
\hline \multicolumn{5}{|c|}{ Weaknesses/ Kelemahan (W) } \\
\hline No & Kelemahan & Bobot & Rating & Skor \\
\hline 1 & $\begin{array}{l}\text { Tempat Pemrosesan Akhir (TPA) Sampah Batu Canai Pematang } \\
\text { Rebah memiliki Anggaran Pengelolaan Sampah terbatas }\end{array}$ & 0.10 & 1 & 0.10 \\
\hline 2 & Jumlah dan keahlian SDM pengelola TPA masih terbatas & 0.20 & 2 & 0.40 \\
\hline 3 & $\begin{array}{l}\text { Tempat Pemrosesan Akhir (TPA) Sampah Batu Canai Pematang Reba } \\
\text { memiliki Pembagian tugas operasional dan maintenance belum dibagi } \\
\text { dengan jelas }\end{array}$ & 0.10 & 2 & 0.20 \\
\hline 4 & $\begin{array}{l}\text { Tempat Pemrosesan Akhir (TPA) Sampah Batu Canai Pematang Reba } \\
\text { memiliki Biaya Operasional pengelolaan TPA (Controlled Landfill) yang } \\
\text { tinggi }\end{array}$ & 0.20 & 3 & 0.60 \\
\hline 5 & $\begin{array}{l}\text { Status Kepemilikan lahan Tempat Pemrosesan Akhir (TPA) Sampah } \\
\text { Batu Canai Pematang Reba yang merupakan lahan pinjaman }\end{array}$ & 0.20 & 3 & 0.60 \\
\hline 6 & $\begin{array}{l}\text { Pemanfaatan teknologi pengolahan sampah tidak optimal pada Tempat } \\
\text { Pemrosesan Akhir (TPA) Sampah Batu Canai Pematang Rebah } \\
\text { memiliki }\end{array}$ & 0.20 & 3 & 0.60 \\
\hline Tot & & 1 & 14 & 2.50 \\
\hline
\end{tabular}

Berdasarkan pada perhitungan kekuatan dan kelemahan yang ada di Tempat Pemrosesan Akhir (TPA) Sampah Batu Canai Pematang Reba, maka dapat dilihat bahwa kelemahan lebih besar dibandingkan kekuatan. Hal ini dapat dilihat dari hasil perkurangan dari kekuatan-kelemahan, yakni sebesar $-0,1$ poin.

\section{Analisis Eksternal (EFAS)}

Analisis Eksternal (EFAS) penting untuk melihat berbagai peluang serta ancaman yang dihadapi oleh TPA. Adapun hasil perhitungan terhadap faktor eksternal Tempat Pemrosesan Akhir (TPA) Sampah Batu Canai Pematang Reba dapat dilihat pada Tabel 8 dan Tabel 9.

Tabel 8. Hasil Perhitungan faktor-faktor Peluang pada Tempat Pemrosesan Akhir (TPA) Sampah Batu Canai Pematang Reba

\begin{tabular}{lllll}
\hline Opportunities (O) & & & \\
\hline No & Peluang & Bobot & Rating & Skor \\
\hline $\mathbf{1}$ & Sumber Sampah & 0.30 & 4 & 1.20 \\
$\mathbf{2}$ & Dukungan dari pemerintah daerah sangat baik & 0.30 & 3 & 0.90 \\
$\mathbf{3}$ & Potensi bisnis daur ulang sampah yang menguntungkan & 0.10 & 3 & 0.30 \\
$\mathbf{4}$ & sampah organic yang bisa dijadikan sebagai bio energy & 0.20 & 3 & 0.60 \\
$\mathbf{3}$ & Pihak swasta yang mendirikan Bank Sampah & 0.10 & 3 & 0.30 \\
\hline Total & Sumber: Data diolah, 2020 & 1.00 & 16 & 3.30 \\
\hline
\end{tabular}

Tabel 9. Hasil Perhitungan faktor-faktor Ancaman pada Tempat Pemrosesan Akhir (TPA) Sampah Batu Canai Pematang Reba

\begin{tabular}{lllll}
\hline Ancaman & & & \\
\hline No & Kekuatan & Bobot & Rating & Skor \\
\hline $\mathbf{1}$ & $\begin{array}{l}\text { Kesadaran masyarakat untuk memilah dan mengelola } \\
\text { sampah masih minim }\end{array}$ & 0.33 & 1 & 0.33 \\
$\mathbf{2}$ & $\begin{array}{l}\text { Perubahan Teknologi pengolahan sampah yang } \\
\text { semakin canggih }\end{array}$ & 0.22 & 2 & 0.44 \\
$\mathbf{3}$ & $\begin{array}{l}\text { Tidak adanya kepastian hukum tentang operasional } \\
\text { TPA }\end{array}$ & 2 & 0.33 \\
$\mathbf{4}$ & $\begin{array}{l}\text { Kurangnya kerja sama antar instansi pemerintah dalam } \\
\text { operasional TPA }\end{array}$ & 0.11 & 2 & 0.67 \\
\hline Total & 1.00 & 7 & 1.67 \\
\hline Sumber: Data diolah, 2020 & & &
\end{tabular}


Berdasarkan pada perhitungan Peluang dan Ancaman yang ada di Tempat Pemrosesan Akhir (TPA) Sampah Batu Canai Pematang Reba, maka dapat dilihat bahwa Peluang lebih besar dibandingkan Ancaman. Hal ini dapat dilihat dari hasil perkurangan dari Peluang-Ancaman yakni sebesar 1.63 poin.

Langkah selanjutnya adalah menelaah melalui diagram analisis SWOT dengan membuat titik potong antara sumbu X dan sumbu Y, dimana nilai dari sumbu X di dapat dari selisih antara total Strengths dan total Weaknesses, sedangkan untuk nilai sumbu Y didapat dari selisih antara total antara Opportunities dan total Threats. Titik potong dituangkan ke dalam kuadran SWOT, maka dapat dilihat pada Gambar 2

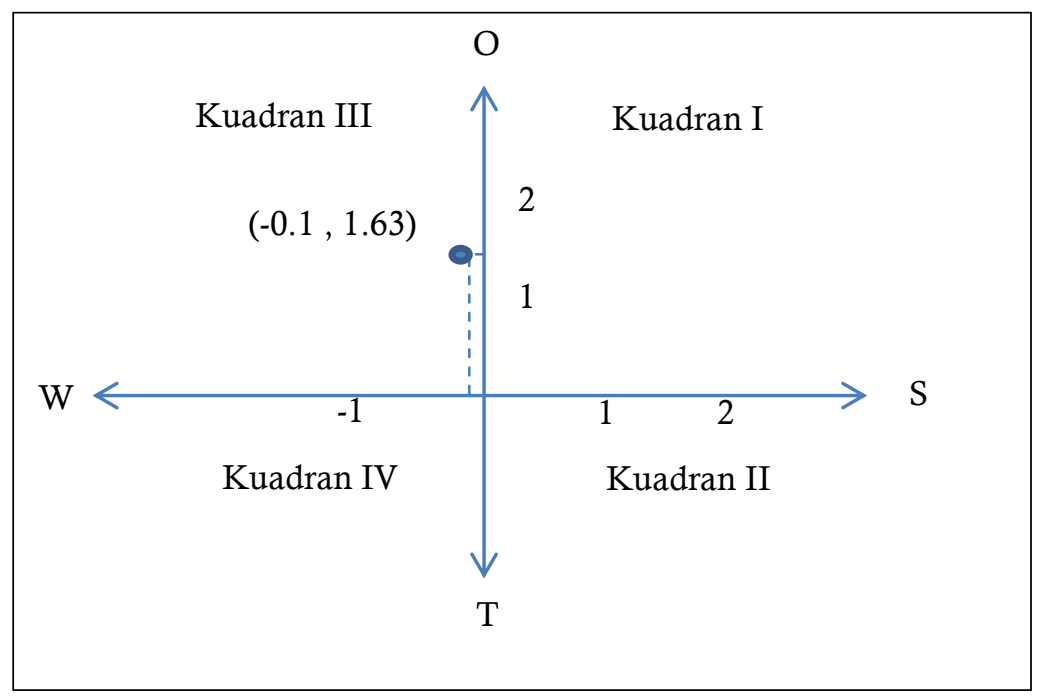

Gambar 2. Kuadran Analisis SWOT

Berdasarkan pada perhitungan kuadran yang ada pada pengolahan TPA, maka dapat dirumuskan berbagai straegi yang dapat digunakan, adalah dengan memperbaiki kelemahan yang ada di Tempat Pemrosesan Akhir (TPA) Sampah Batu Canai untuk meraih peluang yang ada. Sehingga dapat dirumuskan strategi yang di gunakan adalah Strategi W-O pada kudran III.

Menurut Rangkuti (2014) Strategi WO yaitu menciptakan strategi yang meminimalkan kelemahankelemahan yang ada. Strategi W-O merupakan penggabungan atau pencocokan antara faktor internal (kelemahan) dengan faktor eksternal (peluang) dengan cara meminimalkan kelemahan untuk memanfaatkan peluang.

\section{Implementasi Strategi Analisis SWOT Pada Tempat Pemrosesan Akhir (TPA) Sampah Batu Canai Di Kelurahan Pematang Reba}

\section{Optimalisasi biaya operasional Controlled landfill}

Tata Cara Teknik Operasional Pengelolaan Sampah. Adapun teknik operasional untuk efektifitas pengelolaan sampah dengan metode Controlled landfill, adalah dengan mengoptimalkan setiap potensi yang dimiliki oleh TPA, seperti tersedinya sarana dan prasarana yang lengkap. Oleh karena itu, bisa dilakukan dengan beberapa teknik, agar metode pengelolaan Tempat Pemrosesan Akhir (TPA) Sampah Batu Canai dapat mengurangi biaya operasional, yaitu 1) Pengomposan 2) Daur ulang.

Jadi untuk mengantisipasi permasalah Controlled landfill Tempat Pemrosesan Akhir (TPA) Sampah Batu Canai dapat mempertimbangkan beberapah hal 1) Jumlah produksi sampah masih tinggi yang disebabkan oleh implementasi kebijakan $3 \mathrm{R}$ yang tidak berjalan dengan baik, kepedulian masyarakat terhadap sampah yang masih rendah, serta sarana prasarana yang masih perlu untuk ditingkatkan baik dari segi kuantitas maupun kualitas 2)Anggaran yang tersedia yang dialokasikan untuk program-program yang berkaitan dengan pengelolaan sampah harus benar-benar direalisasikan secara maksimal 3) Perlunya dilaksanakan kegiatan untuk meningkatkan kapasitas SDM sebagai pengelola dan tenaga teknis di Tempat Pemrosesan Akhir (TPA) Sampah Batu Canai 4) Menjalankan Standar Prosedur teknik operasional TPA benar-benar sesuai dengan standar yang telah ditetapkan. 
Pembagian tugas operasional dan maintenance harus jelas

Untuk menghindari terjadinya konflik kepentingan serta adanya check and balance yang memastikan pelaksanaan pelayanan persampahan, Permen PU No. 21/PRT/M/2006 Tentang Kebijakan Dan Strategi Nasional Pengembangan Sistem Pengelolaan Persampahan (KSNP-SPP) menyatakan perlu adanya pemisahan peran antara institusi yang berperan sebagai regulator dan institusi yang berperan sebagai operator/ penyelenggara layanan.

Dalam konteks tugas pemerintahan, yang dimaksud dengan regulator adalah pihak yang mengembangkan kebijakan, norma, dan standar, bagi pelaksanaan pelayanan publik. Regulator kemudian juga melakukan fungsi pengawasan dan pengendalian agar pelaksanaan pelayanan publik bisa berjalan sesuai koridor yang telah ditetapkan. Operator, di lain pihak, merupakan pelaksana pelayanan publik (misal: pengelola TPA, pengelola pengangkutan sampah) yang melakukan perencanaan dan implementasi kegiatan sesuai arahan dari regulator.

Peran regulator dan operator harus tercermin dengan jelas pada uraian tugas dan fungsi dari masingmasing institusi. Daerah yang belum dapat memisahkan peran operator menjadi unit kerja tersendiri, maka peran pelayanan persampahan (misalnya: kebersihan jalan/fasilitas umum, pengangkutan sampah dan pengelolaan TPA) tugas fungsinya dapat dilekatkan pada struktur jabatan/posisi yang ada pada Dinas, misal pada "Bidang" atau "Seksi"

\section{Manfaatkan teknologi pengolahan sampah untuk mengolah sampah organik menjadi bio energy}

\section{Teknologi Biodigester}

Alternatif pengolahan sampah yang dapat diterapkan untuk menyelesaikan masalah sampah di TPA adalah memanfaatkan sampah organik dengan teknologi biodigester. Teknologi Biodigester nantinya akan menghasilkan keluaran yang bermanfaat seperti listrik, pupuk dan gas metan. Selain itu teknologi biodigester ini lebih ekonomis dan mudah dalam pelaksanaannya sehingga dapat dijadikan suatu upaya konservasi lingkungan. Dengan adanya alternatif tersebut dapat diperoleh desain biodigester yang disesuaikan dengan volume sampah dan alur perencanaan yang ada. Sehingga mampu mengurangi volume timbulan sampah dan diharapkan tidak ada sampah yang akan dikirim ke TPA mengingat kondisi TPA tidak dapat menampung sampah lagi dalam jangka waktu tertentu. Teknologi ini sebenarnya sangat mungkin diterapkan di Kabupaten Indragiri Hulu karena sampah organiknya persentasenya cukup besar. Namun Pemerintah Daerah harus mempersiapkan sarana prasarana dan SDM yang cukup untuk pelaksanaannya.

\section{Teknologi recycling (daur ulang).}

Teknologi ini pada prinsipnya mengubah sampah yang dapat didaur ulang menjadi barang baru yang bermanfaat. Di Kabupaten Indragiri Hulu sudah ada beberapa kelompok masyarakat yang mengelola Bank Sampah.

\section{Teknologi composting (pengomposan).}

Teknologi pengomposan mengubah sampah organik menjadi kompos. Di Tempat Pemrosesan Akhir (TPA) Sampah Batu Canai sudah memiliki sarana pengomposan yakni rumah kompos dan alat pembuat kompos, namun tidak dipergunakan dengan teknologi yang benar dan keterbatasan SDM yang memiliki keahlian dalam teknik pengomposan. Agar dapat kembali berjalan Pemerintah daerah harus memberikan kegiatan skala prioritasdan dukungan untuk menerapkan teknologi ini.

\section{TPA menjadi Unit Pelaksana Teknis Daerah(UPTD) atau Badan Layanan Umum Daerah (BLUD)}

Bentuk lembaga atau instansi pengelola sampah di daerah saat ini masih beragam. Menurut Damanhuri dan Padmi (2011) bentuk lembaga pengelolaan persampahan kota yang dianut di Indonesia selama ini antara lain: a. Seksi Kebersihan di bawah satu dinas, misal Dinas Pekerjaan Umum terutama apabila masalah kebersihan kota masih bisa ditanggulangi oleh suatu seksi di bawah dinas tersebut; $b$. Unit Pelaksana Teknis Dinas (UPTD) di bawah suatu dinas, misalnya Dinas Pekerjaan Umum terutama apabila dalam struktur organisasi belum ada seksi khusus di bawah dinas yang mengelola kebersihan sehingga lebih memberikan tekanan pada masalah operasional, dan lebih mempunyai otonomi daripada seksi; c. Dinas Kebersihan, merupakan OPD yang akan memberikan percepatan dan pelayanan pada masyarakat dan bersifat nirlaba. Dinas ini dibentuk karena aktivitas dan volume pekerjaan yang sudah meningkat; d. 


\section{ZONA}

Jurnal Lingkungan

ISSN : 2502-6496 (Print)

Volume 4, No 2, Oktober 2020, p. 78-90

http://zona.pelantarpress.co.id

Perusahaan Daerah (PD) Kebersihan, merupakan organisasi pengelola yang dibentuk bila permasalahan di kota tersebut sudah cukup luas dan kompleks. Pada prinsipnya PD Kebersihan ini tidak lagi disubsidi oleh pemerintah daerah sehingga efektivitas penarikan retribusi akan lebih menentukan. Ada berbagai macam bentuk kelembagaan yang dapat di terapkan di Kabupaten Indragiri Hulu. Jadi tergantung kebijakan Pemerintah Daerah pengelolaan persampahan dan TPA serahkan kepada OPD dalam bentuk UPTD atau dengan membentuk lembaga independen pengelola TPA.

Sebuah UPTD hanya menerima anggaran operasional dari pemerintah Kabupaten/Kota, maka tantangan berikutnya adalah bagaimana membuat pendapatan UPTD ini dapat menutup semua biaya operasionalnya sebelum UPTD nantinya dikembangkan menjadi Badan Layanan Umum Daerah (BLUD). Karena ketika TPA telah mampu mengembangkan berbagai inovasi dalam pengelolaan pemrosesan akhir sampah TPA akan membutuhkan investasi yang cukup besar.

\section{Pemberdayaan Masyarakat Partisipatif}

Partisipasi masyarakat dalam pengelolaan sampah dapat meningkatkan kesadaran masyarakat akan pentingnya kebersihan lingkungan yang hijau, bersih dan sehat serta menguatkan inisiatif masyarakat dalam menjaga, memelihara dan meningkatkan fungsi lingkungan

Salah satu bentuk kegiatan partisipatif masyarakat adalah melalui Bank Sampah. Fungsi dari Bank Sampah yaitu merupakan tempat menabung sampah yang telah terpilah menurut jenis sampah, sampah yang ditabung pada bank sampah adalah sampah yang mempunyai nilai ekonomis. Cara kerja bank sampah pada umumnya hampir sama dengan bank lainnya, ada nasabah, pencatatan pembukuan dan manajemen pengelolaannya, apabila dalam bank yang biasa kita kenal yang disetorkan nasabah adalah uang. Akan tetapi, dalam bank sampah yang disetorkan adalah sampah yang mempunyai nilai ekonomis, sedangkan pengelola bank sampah harus orang yang kreatif dan inovatif serta memiliki jiwa kewirausahaan agar dapat meningkatkan pendapatan masyarakat.

Saat ini Kabupaten Indragiri Hulu sudah memilik 3 Bank sampah yang dikelola oleh masyarakat. Bank sampah yang ada ini adalah hasil dari binaan Dinas Lingkungan Hidup Kabupaten Indragiri Hulu. Ada anggaran yang dialokasikan untuk membina masyarakat yang ingin berpartisipasi dalam Bank Sampah dan Dinas Lingkungan Hidup juga pernah meberikan bantuan berupa prasarana peralatan pendukung seperti mesin jahit dan bagi pengelola Bank Sampah diberikan honorarium setiap bulannya dan bimbingan teknis serta sosialisasi kepada masyarakat tentang Bank Sampah.

\section{KESIMPULAN}

Kondisi eksisting Tempat Pembuangan Akhir (TPA) Sampah Batu Canai Pematang Reba Kecamatan Rengat Barat sudah menggunakan sistem Controlled landfill. Berdasarkan perhitungan prediksi diatas dapat diketahui masa layanan sampah dapat di terima pada Tahun 2028 pada bulan ke 9 sehingga total dari tahun 2020 untuk Tempat Pembuangan Akhir (TPA) Sampah Batu Canai Di Kelurahan Pematang Reba dapat melayani hingga 8 tahun 9 bulan. Persentase reduksi pemulung diasumsikan $5 \%$ dari total sampah yang masuk pertahunnya..

Dampak negatif keberadaan TPA adanya bau yang timbul jika kondisi hujan dan sampah yang berceceran. Pencemaran air tanah belum ada dampak yang terlihat dikarenakan masyarakat tidak mengkonsumsi air tanah terebut. Sampah yang terbuka menimbulkan munculnya lalat yang dapat mengganggu serta menyebarkan penyakit. Terhadap sosial perilaku masyarakat dan pemulung yang bekerja di TPA kurang memperhatikan kebersihan dan tidak menggunakan perlengkapan yang dapat memproteksi dari timbulnya penyakit. Serta dampak positif yang ditimbulkan adalah adanya pekerjaan yang dapat menghasilkan uang dalam mengumpulkan sampah yang masih layak serta masih memiliki nilai jual yang tinggi, sehingga dapat meningkatkan perekonomian masyarakat di sekitar TPA.

Strategi pengelolaan sampah pada Tempat Pembuangan Akhir (TPA) Sampah Batu Canai Pematang Reba harus menerapkan strategi WO. Strategi W-O merupakan penggabungan atau pencocokan antara faktor internal (kelemahan) dengan faktor eksternal (peluang) dengan cara meminimalkan kelemahan untuk memanfaatkan peluang, dengan alternatif strategi sebagai berikut: 1) Optimalkan biaya operasional Controlled landfill. 2) Pembagian tugas operasioanal dan maintenance harus jelas untuk mendapatkan dukungan yang baik dari pemerintah daerah. 3) Manfaatkan teknologi pengolahan sampah 


\section{ZONA}

Jurnal Lingkungan

Volume 4, No 2, Oktober 2020, p. 78-90

ISSN : 2502-6496 (Print)

http://zona.pelantarpress.co.id

yang baik untuk mengolah sampah organic menjadi bio energy. 4) TPA pengelolaannya menjadi UPTD atau BLUD 5) Pemberdayaan masyarakat partisipatif.

\section{DAFTAR PUSTAKA}

Aji, R.W. 2019. Strategi Pengelolaan Sampah Rumah Tangga di Kabupaten Cilacap Jawa Tengah. Jurnal Manajemen dan Ekonomi, 2(2) : 213-224

Damanhuri ,E dan Padmi, T. 2004. Diktat Pengelolaan Sampah. Teknik Lingkungan Institut Teknologi Bandung (ITB). Bandung

Handono M. 2010. Model Pengelolaan Tempat Pemrosesan Akhir (TPA) Sampah Secara Berkelanjutan Di TPA Cipayung Kota Depok-Jawa Barat. Disertasi. Sekolah Pascasarjana. Institut Pertanian Bogor.

Kasam. 2011. Analisis Resiko Lingkungan pada Tempat Pembuangan Akhir (TPA) Sampah (Studi Kasus: TPA Piyungan Bantul). Jurnal Sains dan Teknologi Lingkungan, 3(1) : 19-30

Rangkuti, F. 2014. ANALISIS SWOT : Teknik Membedah Kasus Bisnis. PT. Gramedia Pustaka Utama. Jakarta. 